\title{
Should we use gait speed in COPD, FEV1 in frailty and dyspnoea in both?
}

\author{
Jean Bousquet ${ }^{1,2,3,4}$, Anh Tuan Dinh-Xuan ${ }^{5}$, Thomas Similowski ${ }^{6}$, João Malva ${ }^{7}$, \\ Joël Ankri ${ }^{8}$, Mario Barbagallo ${ }^{9}$, Leonardo Fabbri ${ }^{10}$, Marc Humbert $^{11}$, \\ Jacques Mercier ${ }^{12}$, Carlos Robalo-Cordeiro ${ }^{13}$, Leocadio Rodriguez-Manas ${ }^{14}$ and \\ Bruno Vellas ${ }^{15}$
}

Affiliations: ${ }^{1}$ MACVIA-LR, Contre les Maladies Chroniques pour un Vleillissement Actif en LanguedocRoussillon, Languedoc-Roussillon, France. ${ }^{2}$ European Innovation Partnership on Active and Healthy Ageing Reference Site, Montpellier, France. ${ }^{3}$ INSERM, VIMA: Ageing and chronic diseases, Epidemiological and public health approaches, U1168, Paris, France. ${ }^{4}$ UVSQ, UMR-S 1168, Université Versailles St-Quentin-en-Yvelines, Versailles, France. ${ }^{5}$ Service de physiologie respiratoire, Hôpital Cochin, Université Paris-Descartes, Assistance publique-Hôpitaux de Paris, Paris, France. 'UUMRS 1158 Neurophysiologie Respiratoire Expérimentale et Clinique, Sorbonne Universités, UPMC Univ Paris 06, INSERM, Paris, France. ${ }^{7}$ Institute of Biomedical Imaging and Life Sciences (IBILI), Faculty of Medicine, University of Coimbra, Coimbra, Portugal. ${ }^{8}$ Gerontology Center, Site Sainte Périne, Université de Versailles St Quentin, Paris, France. ${ }^{9}$ Dept of Internal Medicine (DIBIMIS), University of Palermo, Palermo, Italy. ${ }^{10}$ Dept of Metabolic Medicine, University of Modena and Reggio Emilia, Sant'Agostino Estense Hospital, Modena, Italy. ${ }^{11}$ Université Paris-Sud, Service de Pneumologie, Hôpital Bicêtre, Le Kremlin Bicêtre, France. ${ }^{12}$ Dept of Physiology, CHRU, University Montpellier, INSERM U1046, CNRS UMR 9214, Montpellier, France. ${ }^{13}$ Centre of Pneumology, Coimbra University Hospital, Coimbra, Portugal. ${ }^{14}$ Dept of Geriatrics, Getafe University Hospital, Madrid, Spain. ${ }^{15}$ Gérontopôle de Toulouse, Toulouse, France.

Correspondence: Jean Bousquet, CHRU Arnaud de Villeneuve, Département de Pneumologie, 371 Avenue du Doyen Gaston Giraud, 34295 Montpellier, Cedex 5, France. E-mail: jean.bousquet@orange.fr

-

@ERSpublications

Links between frailty, dyspnoea and chronic respiratory diseases represent a novel and practical approach http://ow.ly/10zIvj

Frailty is a progressive physiological decline in multiple organ systems marked by loss of function, loss of physiological reserve and increased vulnerability to disease [1]. Biological (inflammation and loss of hormones), clinical (e.g. sarcopenia and osteoporosis) and social factors are involved in frailty onset, evolution and prognosis $[2,3]$.

Many chronic diseases are associated with frailty and functional decline in older people [4]. Older people suffering from frailty often receive fragmented chronic care from multiple professionals. Coordination of care using a multidimensional approach is needed to develop interventions aimed at reducing frailty. Chronic respiratory diseases (CRD) represent a model of chronic diseases across the life course [5]. As with any noncommunicable disease, they can be associated with frailty [6]. It is possible that markers of frailty (gait speed) or CRD (pulmonary function tests) can be used in both frailty and CRD as independent markers for severity and trajectories. Moreover, they may represent interesting outcome measures adding value in clinical practice but that have been underestimated.

$\mathrm{CRD}$ and frailty are key targets of good practices emerging from the European Innovation Partnership on Active and Healthy Ageing (EIP-AHA) [7, 8]. Links between them represent a novel and practical approach between action groups of the EIP-AHA.

\section{Frailty in COPD}

Chronic obstructive pulmonary disease can be associated with frailty

Unrecognised chronic obstructive pulmonary disease (COPD) may be detected in community-dwelling frail elderly people using a near-home screening strategy that is simple to implement [9]. Patients with chronic

Received: March 302016 | Accepted: March 302016

Conflict of interest: Disclosures can be found alongside the online version of this article at erj.ersjournals.com

Copyright OERS 2016 
lung disease frequently meet the criteria of Fried for frailty [10]. Sarcopenia affects up to $15 \%$ of patients with stable COPD and impairs function and health status [11]. Many patients with COPD are frail [12] and physical activity level can predict the absence or presence of frailty in subjects with stable and exacerbated COPD [13]. In the Cardiovascular Health Study, frailty and respiratory impairment (airflow limitation or restrictive pattern) are strongly associated with one another and substantially increase the risk of death when both are present [14]. Establishing these associations may inform interventions designed to reverse or prevent the progression of either condition and reduce adverse outcomes.

It remains to be proven, however, whether optimising treatment of frail COPD patients with multimorbidities and polypharmacy improves health outcomes. Integrated care services in frail community-dwelling COPD patients improved clinical outcomes such as survival and decreased the emergency department visits, but it did not reduce hospital admissions [15].

\section{Gait speed is a surrogate marker of COPD management and prognosis}

Gait speed, a key marker of frailty, is mainly determined by exercise capacity but also reflects global well-being and may capture many of the multi-systemic effects of disease severity in COPD rather than pulmonary impairment alone. The usual gait speed is correlated with the 6-min walk distance (6MWD) [16]. Gait speed may be used as a functional capacity indicator in COPD patients [17]. The reliability and validity of the 4-m gait speed was demonstrated in patients with COPD. Gait speed slows down with increasing COPD severity. It correlates with age, clinical symptoms, pulmonary functions and quality of life scores. In community-dwelling elderly people, gait speed is a consistent predictor of adverse outcomes in patients with COPD [18]. It independently predicts the risk of readmission in older patients hospitalised for COPD [19]. The changes in usual gait speed and 6MWD are associated with increased mortality in patients with severe COPD [20]. Gait speed is promising as a simple test that can inform the clinician about many important functional aspects of the COPD patient [21] and be used in primary care [22].

\section{Prognostic value of pulmonary function in nonrespiratory chronic diseases and older aged adults}

COPD is commonly associated with cardiovascular diseases (CVDs) since they share many common pathogenic mechanisms [23]. CVD is the most common cause of death in COPD. It has long been known that obstructive and restrictive lung diseases are significant predictors of earlier death $[24,25]$.

\section{Nonrespiratory chronic diseases}

Forced expiratory volume in $1 \mathrm{~s}$ (FEV1) is an independent predictor of all-cause and CVD mortality [26-30]. The addition of global CVD risk scores to lung function data significantly improves risk stratification of patients with COPD for CVD and total mortality [31]. Diabetes mellitus is associated with decreased pulmonary function. Reduced lung function is inversely related to blood glucose levels, diabetes duration and severity, and is independent of smoking or obesity [32]. Pulmonary function is a risk factor for other nonrespiratory diseases such as dementia [33]. Thus, FEV1 appears to be an independent risk factor for nonrespiratory diseases $[34,35]$ and may be considered as a measure of physiological health that may improve risk stratification of noncommunicable disease patients.

Chronic airflow obstruction results in impaired lung gas exchange and hypoxia [36]. Hypoxia plays a key role in the pathophysiology of CVD, cancer, stroke and other causes of mortality. Hypoxia impedes cellular oxygen consumption and, more importantly, triggers various molecular and cellular responses leading to metabolic reprogramming and inflammatory responses [37]. As a result, the function of many organs or systems, including the kidneys, central nervous system, cardiovascular system, skeletal muscles and even the immune system, are affected by chronic hypoxic insult [38]. This might explain some of the links between impaired lung function and extrathoracic organ disorders [39]. Hypoxia has pervasive effects on the function of adipocytes and appears to be a key factor in adipose tissue dysfunction in obesity [40].

These considerations need to be better understood and confirmed by other trials but they open new fields of interest and research for improved management of all patients.

\section{Older aged adults}

There are many age-associated changes in the respiratory system physiology and immunology [41] that impact on pulmonary function $[42,43]$. In healthy ageing there is a steady decline of dynamic lung volumes that does not limit oxygen transport and uptake [44]. Expiratory flow is reduced and the flowvolume curve may resemble COPD [45]. Moreover, the criteria used to define the various stages of COPD or restrictive pattern need to be age specific $[45,46]$. Alternatives of FEV1 (e.g. FEV1/FEV6 or FEV1 divided by height cubed [3]) have been proposed in this age group [47, 48]. Thus, FEV1 should not be considered as a diagnostic tool or a measure of severity of CRD with the criteria used in adults. 
A few studies in older aged adults have used spirometry-based parameters for prognosis beyond respiratory morbidity and mortality [49]. A low FEV1 is a significant predictor of all-cause mortality in older people [47]. In very old adults, low FEV1 divided by height [3] is a predictor of all-cause mortality and hospitalisation independently of age, smoking status, chronic lung disease and other comorbidities [48].

FEV1 and forced vital capacity are inversely associated with risk of future CVD events in older adults and may add to CVD risk stratification [50]. In the Berlin Aging Study II, type 2 diabetes and metabolic syndrome were associated with decreased lung volumes [51]. Muscle mass and abdominal obesity were the most important factors influencing pulmonary function. Measurement of grip strength for the determination of muscle mass and waist circumference for determining abdominal obesity could contribute to the interpretation of the results of pulmonary function tests. In this group, levels of lipoprotein(a), a lipid parameter independently associated with CVD, are not associated with the increased CVD risk in people with reduced lung function [52],

Due to the strong and consistent association with mortality, pulmonary function has been viewed as a biomarker of ageing [53]. Lung function in individuals with exceptional longevity has been associated with rare genetic variants underlying the linkage peak in chromosome 6 for FEV1 [54]. However, more data are needed to consider FEV1 and its alternatives as a measure of physiological health in older adults that may improve prognosis of frail older adults.

However, we need to disconnect pulmonary function from lung diseases in adults and older aged people and use some parameters as indicators of noncommunicable disease prognosis across the life cycle or frailty in older aged adults, irrespective of lung diseases.

\section{Dyspnoea as a common entry point for the clinician}

One possible candidate among such parameters is dyspnoea, a ubiquitous and nonspecific symptom. It is a major determinant of poor quality of life in all CRDs, many CVDs, neuromuscular disorders and in severe obesity [55]. Dyspnoea may also relate to ageing and frailty, independently of organ-specific disorders. Muscle deconditioning and sarcopenia, alone or in combination with reduced ventilatory and lung vascular reserves, constitute a mechanism for age-related exertional dyspnoea. In older aged adults, dyspnoea is associated with frailty and reduced proximal muscle function independently of spirometric data [56]. Dyspnoea can contribute to frailty both by accelerating muscle loss (according to the same type of vicious dyspnoea-deconditioning-dyspnoea circle in COPD) and by increasing social isolation through dyspnoea-related reduction in activities and relationships.

Identifying dyspnoea in older aged adults prompts a respiratory and cardiac work-up as a standard medical response. In the future, it might also prompt a wider assessment that would include frailty. In addition, dyspnoea is an independent predictor for mortality in COPD [57] and CVD [58], but also in the general population [59] and for all-cause mortality in older aged adults [60-62].

Thus, dyspnoea appears as an entry point to identify specific physiological disorders and nonspecific conditions, such as frailty in older adults, and could prove a simple tool to prioritise decisions. Of note, dyspnoea spontaneous self-report is reduced and qualitatively modified in older aged $[63,64]$ in a manner similar to pain $[65,66]$. This has two clinical consequences: 1) a spontaneous complaint of dyspnoea in older aged adults should represent as an important alert and be considered carefully; and 2) dyspnoea should probably be sought proactively and in a systematic manner by all caregivers dealing with older aged adults [67]. This could have positive impacts beyond symptom management, by improving the identification of both specific diseases and frailty.

\section{Relevance to the EIP on AHA}

As populations continue to age, efforts to support the process of ageing well are important goals. Ageing is intertwined with socioeconomic inequalities, providing an under-appreciated cause of poverty, and hinders economic development, particularly of underserved populations and women. Active and healthy ageing is a major societal challenge that is common in all countries and in all populations [68] Active and healthy ageing allows people to realise their potential for physical, social (economic, cultural, spiritual and civic affairs) and mental wellbeing throughout the life course.

Action Plan A3 of the EIP on AHA is helping to prevent functional decline and frailty whereas Action Plan B3 is promoting integrated care models for chronic diseases The objective of the Integrated Care Pathways for Airway Diseases (AIRWAYS-ICPs) [8] is to launch a collaboration to develop multisector care pathways for CRD in European countries and regions as part of the EIP on AHA (Area 5 of Action Plan B3) and to scale up globally in order to: 1) reduce the burden of the CRD; and 2) promote active healthy ageing using innovative approaches. 
Synergies between action plans are needed and the links between COPD and frailty represent one of the first synergies proposed for the renovated action plan of the EIP on AHA.

In order to foster discussion about key determinants of CRD and frailty and to highlight good practices for replicability and scaling-up, an EIP on AHA meeting was organised by the Région Languedoc-Roussillon (Languedoc-Roussillon, France) [69] and Region Centro Portugal (Lisbon, Portugal) on July 1-2, 2015. This was followed by a meeting on December 7-8, 2015 in Montpellier (France) that considered possible synergies between actions groups of the EIP on AHA.

A synergy entitled "CRDs in old age people: an under-recognized societal problem" (J. Bousquet, unpublished data) has been approved by a Task Force of the EIP. One of the key actions will be to make practical recommendations and implement the links between COPD and frailty.

\section{References}

Rodriguez-Manas L, Fried LP. Frailty in the clinical scenario. Lancet 2015; 385: e7-e9.

Morley JE, Vellas B, van Kan GA, et al. Frailty consensus: a call to action. J Am Med Dir Assoc 2013; 14: 392-397.

Gobbens RJ, van Assen MA, Luijkx KG, et al. Determinants of frailty. J Am Med Dir Assoc 2010; 11: 356-364.

Sinclair A, Morley JE, Rodriguez-Manas L, et al. Diabetes mellitus in older people: position statement on behalf of the International Association of Gerontology and Geriatrics (IAGG), the European Diabetes Working Party for Older People (EDWPOP), and the International Task Force of Experts in Diabetes. J Am Med Dir Assoc 2012; 13: 497-502.

5 Bousquet J, Anto JM, Berkouk K, et al. Developmental determinants in non-communicable chronic diseases and ageing. Thorax 2015; 70: 595-597.

6 Cesari M, Costanzo L, Giua R, et al. Physical function and exercise in older patients with cardiovascular and respiratory conditions. Curr Pharm Des 2014; 20: 3198-3214.

7 Bousquet J, Michel J, Standberg T, et al. The European Innovation Partnership on Active and Healthy Ageing: the European Geriatric Medicine introduces the EIP on AHA Column. Eur Geriatr Med 2014; 5: 361-362.

8 Bousquet J, Addis A, Adcock I, et al. Integrated care pathways for airway diseases (AIRWAYS-ICPs). Eur Respir J 2014; 44: 304-323.

9 Bertens LC, Reitsma JB, van Mourik Y, et al. COPD detected with screening: impact on patient management and prognosis. Eur Respir J 2014; 44: 1571-1578.

10 Mittal N, Raj R, Islam EA, et al. The frequency of frailty in ambulatory patients with chronic lung diseases. J Prim Care Community Health 2016; 7: 10-15.

11 Jones SE, Maddocks M, Kon SS, et al. Sarcopenia in COPD: prevalence, clinical correlates and response to pulmonary rehabilitation. Thorax 2015; 70: 213-218.

12 Lahousse L, Ziere G, Verlinden VJ, et al. Risk of frailty in elderly with COPD: a population-based study. J Gerontol A Biol Sci Med Sci 2016; 71: 689-695.

13 Valenza MC, Torres-Sanchez I, Cabrera-Martos I, et al. Physical activity as a predictor of absence of frailty in subjects with stable COPD and COPD exacerbation. Respir Care 2016; 61: 212-219.

14 Vaz Fragoso CA, Enright PL, McAvay G, et al. Frailty and respiratory impairment in older persons. Am J Med 2012; 125: 79-86.

15 Hernandez C, Alonso A, Garcia-Aymerich J, et al. Integrated care services: lessons learned from the deployment of the NEXES project. Int J Integr Care 2015; 15: e006.

16 DePew ZS, Karpman C, Novotny PJ, et al. Correlations between gait speed, 6-minute walk distance, physical activity, and self-efficacy in patients with severe chronic lung disease. Respir Care 2013; 58: 2113-2119.

17 Ilgin D, Ozalevli S, Kilinc O, et al. Gait speed as a functional capacity indicator in patients with chronic obstructive pulmonary disease. Ann Thorac Med 2011; 6: 141-146.

18 Kon SS, Patel MS, Canavan JL, et al. Reliability and validity of 4-metre gait speed in COPD. Eur Respir J 2013; 42: 333-340.

19 Kon SS, Jones SE, Schofield SJ, et al. Gait speed and readmission following hospitalisation for acute exacerbations of COPD: a prospective study. Thorax 2015; 70: 1131-1137.

20 Benzo R, Siemion W, Novotny P, et al. Factors to inform clinicians about the end of life in severe chronic obstructive pulmonary disease. J Pain Symptom Manage 2013; 46: 491-499.

21 Karpman C, Benzo R. Gait speed as a measure of functional status in COPD patients. Int J Chron Obstruct Pulmon Dis 2014; 9: 1315-1320.

22 Kon SS, Canavan JL, Nolan CM, et al. The 4-metre gait speed in COPD: responsiveness and minimal clinically important difference. Eur Respir J 2014; 43: 1298-1305.

23 Fabbri LM, Rabe KF. From COPD to chronic systemic inflammatory syndrome? Lancet 2007; 370: 797-799.

24 Mannino DM, Buist AS, Petty TL, et al. Lung function and mortality in the United States: data from the First National Health and Nutrition Examination Survey follow up study. Thorax 2003; 58: 388-393.

25 Mattila T, Vasankari T, Kanervisto M, et al. Association between all-cause and cause-specific mortality and the GOLD stages 1-4: a 30-year follow-up among Finnish adults. Respir Med 2015; 109: 1012-1018.

26 Sunyer J, Ulrik CS. Level of FEV1 as a predictor of all-cause and cardiovascular mortality: an effect beyond smoking and physical fitness? Eur Respir J 2005; 25: 587-588.

27 Min KB, Min JY. Reduced lung function, C-reactive protein, and increased risk of cardiovascular mortality. Circ J 2014; 78: 2309-2316.

28 Shibata Y, Inoue S, Igarashi A, et al. A lower level of forced expiratory volume in 1 second is a risk factor for all-cause and cardiovascular mortality in a Japanese population: the Takahata study. PLoS One 2013; 8: e83725.

29 Menezes AM, Perez-Padilla R, Wehrmeister FC, et al. FEV1 is a better predictor of mortality than FVC: the PLATINO cohort study. PLoS One 2014; 9: e109732.

30 Smith M, Zhou M, Wang L, et al. Peak flow as a predictor of cause-specific mortality in China: results from a 15-year prospective study of 170,000 men. Int J Epidemiol 2013; 42: 803-815. 
31 Lee HM, Lee J, Lee K, et al. Relation between COPD severity and global cardiovascular risk in US adults. Chest 2012; 142: 1118-1125.

32 Klein OL, Krishnan JA, Glick S, et al. Systematic review of the association between lung function and type 2 diabetes mellitus. Diabet Med 2010; 27: 977-987.

33 Russ TC, Starr JM, Stamatakis E, et al. Pulmonary function as a risk factor for dementia death: an individual participant meta-analysis of six UK general population cohort studies. J Epidemiol Community Health 2015; 69: 550-556.

34 Li J, Agarwal SK, Alonso A, et al. Airflow obstruction, lung function, and incidence of atrial fibrillation: the Atherosclerosis Risk in Communities (ARIC) study. Circulation 2014; 129: 971-980.

35 Johnson LS, Juhlin T, Engstrom G, et al. Reduced forced expiratory volume is associated with increased incidence of atrial fibrillation: the Malmo Preventive Project. Europace 2014; 16: 182-188.

36 Macklem PT. La physiopathologie de la limitation au passage du courant aérien [Physiopathology of the limitation of airflow]. Bull Int Union Tuberc 1978; 53: 167-171.

37 Stenmark KR, Tuder RM, El Kasmi KC. Metabolic reprogramming and inflammation act in concert to control vascular remodeling in hypoxic pulmonary hypertension. J Appl Physiol (1985) 2015; 119: 1164-1172.

38 Farias JG, Herrera EA, Carrasco-Pozo C, et al. Pharmacological models and approaches for pathophysiological conditions associated with hypoxia and oxidative stress. Pharmacol Ther 2016; 158: 1-23.

39 Takiyama Y, Haneda M. Hypoxia in diabetic kidneys. Biomed Res Int 2014; 2014: 837421.

40 Trayhurn P. Hypoxia and adipose tissue function and dysfunction in obesity. Physiol Rev 2013; 93: 1-21.

41 Meiners S, Eickelberg O, Königshoff M. Hallmarks of the ageing lung. Eur Respir J 2015; 45: 807-827.

42 Janssens JP. Aging of the respiratory system: impact on pulmonary function tests and adaptation to exertion. Clin Chest Med 2005; 26: 469-484.

43 Vaz Fragoso CA, McAvay G, Van Ness PH, et al. Aging-related considerations when evaluating the forced expiratory volume in 1 second (FEV1) over time. J Gerontol A Biol Sci Med Sci 2015; [in press DOI: 10.1093/ gerona/glv201].

44 Hassel E, Stensvold D, Halvorsen T, et al. Association between pulmonary function and peak oxygen uptake in elderly: the Generation 100 study. Respir Res 2015; 16: 156.

45 Hardie JA, Buist AS, Vollmer WM, et al. Risk of over-diagnosis of COPD in asymptomatic elderly never-smokers Eur Respir J 2002; 20: 1117-1122.

46 Vaz Fragoso CA, McAvay G, Van Ness PH, et al. Phenotype of spirometric impairment in an aging population. Am J Respir Crit Care Med 2016; 193: 727-735.

47 Sorino C, Sherrill D, Guerra S, et al. Prognostic value of FEV1/FEV6 in elderly people. Clin Physiol Funct Imaging 2011; 31: 101-107.

48 Turkeshi E, Vaes B, Andreeva E, et al. Airflow limitation by the Global Lungs Initiative equations in a cohort of very old adults. Eur Respir J 2015; 46: 123-132.

49 Jacobsen PK, Sigsgaard T, Pedersen OF, et al. Lung function as a predictor of survival in very elderly people: the Danish 1905 cohort study. J Am Geriatr Soc 2008; 56: 2150-2152.

50 Lee HM, Liu MA, Barrett-Connor E, et al. Association of lung function with coronary heart disease and cardiovascular disease outcomes in elderly: the Rancho Bernardo study. Respir Med 2014; 108: 1779-1785.

51 Buchmann N, Norman K, Steinhagen-Thiessen E, et al. Lung function in elderly subjects with metabolic syndrome and type II diabetes: data from the Berlin Aging Study II. Z Gerontol Geriatr 2015; [in press DOI: $10.1007 /$ s00391-015-0959-z]

52 Buchmann N, Kassner U, Norman K, et al. Higher lipoprotein (a) levels are associated with better pulmonary function in community-dwelling older people: data from the Berlin Aging Study II. PLoS One 2015; 10: e0139040.

53 Hollenberg M, Yang J, Haight TJ, et al. Longitudinal changes in aerobic capacity: implications for concepts of aging. J Gerontol A Biol Sci Med Sci 2006; 61: 851-858.

54 Thyagarajan B, Wojczynski M, Minster RL, et al. Genetic variants associated with lung function: the long life family study. Respir Res 2014; 15: 134.

55 Parshall MB, Schwartzstein RM, Adams L, et al. An official American Thoracic Society statement: update on the mechanisms, assessment, and management of dyspnea. Am J Respir Crit Care Med 2012; 185: 435-452.

56 Vaz Fragoso CA, Araujo K, Leo-Summers L, et al. Lower extremity proximal muscle function and dyspnea in older persons. J Am Geriatr Soc 2015; 63: 1628-1633.

57 Nishimura K, Izumi T, Tsukino M, et al. Dyspnea is a better predictor of 5-year survival than airway obstruction in patients with COPD. Chest 2002; 121: 1434-1440.

58 Abidov A, Rozanski A, Hachamovitch R, et al. Prognostic significance of dyspnea in patients referred for cardiac stress testing. N Engl J Med 2005; 353: 1889-1898.

59 Pesola GR, Argos M, Chinchilli VM, et al. Dyspnoea as a predictor of cause-specific heart/lung disease mortality in Bangladesh: a prospective cohort study. J Epidemiol Community Health 2016; [in press DOI: 10.1136/jech-2015-206199].

60 Ahmed T, Steward JA, O'Mahony MS. Dyspnoea and mortality in older people in the community: a 10-year follow-up. Age Ageing 2012; 41: 545-549.

61 Berraho M, Nejjari C, El Rhazi K, et al. Dyspnea: a strong independent factor for long-term mortality in the elderly. J Nutr Health Aging 2013; 17: 908-912.

62 Edjolo A, Helmer C, Barberger-Gateau P, et al. Becoming a nonagenarian: factors associated with survival up to 90 years old in 70+ men and women. Results from the PAQUID longitudinal cohort. J Nutr Health Aging 2013; 17: 881-892.

63 Petersen S, von Leupoldt A, Van den Bergh O. Geriatric dyspnea: doing worse, feeling better. Ageing Res Rev 2014; 15: 94-99.

64 Silvestri GA, Mahler DA. Evaluation of dyspnea in the elderly patient. Clin Chest Med 1993; 14: 393-404

65 Gagliese L. Pain and aging: the emergence of a new subfield of pain research. J Pain 2009; 10: 343-353.

66 Gibson SJ, Farrell M. A review of age differences in the neurophysiology of nociception and the perceptual experience of pain. Clin J Pain 2004; 20: 227-239.

67 Banzett RB, O’Donnell CR. Should we measure dyspnoea in everyone? Eur Respir J 2014; 43: 1547-1550.

68 Rechel B, Grundy E, Robine JM, et al. Ageing in the European Union. Lancet 2013; 381: 1312-1322.

69 Bousquet J, Bourquin C, Augé P, et al. MACVIA-LR Reference Site of the European Innovation Partnership on Active and Healthy Ageing. Eur Geriatr Med 2014; 5: 406-415. 